Editorial

\title{
Effect of vitamin D supplementation in children with severe acute malnutrition in a nutritional rehabilitation centre: a randomized controlled trial
}

\author{
Maurya M. ${ }^{1}$, Sharma P. ${ }^{2}$, Srivastava A. ${ }^{3}$, Rai R. ${ }^{4}$, Singh D.K. ${ }^{5}$ \\ ${ }^{1}$ Dr. Manisha Maurya, Assistant Professor, ${ }^{2}$ Dr. Priya Sharma, Junior resident, ${ }^{3}$ Dr. Anubha Srivastava, Assistant \\ Professor, ${ }^{4}$ Dr. Ruchi Rai, Professor, ${ }^{5}$ Dr. D. K. Singh, Professor and Head, all authors are affiliated with Department of \\ Pediatrics, MLN Medical College, Allahabad, UP, India.
}

Corresponding Author: Dr. Manisha Maurya, Assistant Professor, Department of Pediatrics, MLN Medical College, Allahabad, UP, India. Email: drmanisha99@yahoo.com

\begin{abstract}
Background: According to World Health Organization (2013) approximately 35\% of the under-fivemortalities are due to nutrition related factors \& $4.4 \%$ of deaths are due to severe wasting. It has been found that Vitamin D levels are low in children with malnourished and very sick children. Even the prevalence of vitamin D deficiency is very high in Indian subcontinent. In WHO recommendations for the management of severe acute malnutrition there is no role of vitamin D supplementation. Objective: To study the effect of vitamin D supplementation on severe acute malnourished children admitted in nutritional rehabilitation Centre. Design: Single blinded Randomized controlled, parallel group trial. Setting: Nutritional Rehabilitation Centre (NRC) of a tertiary care hospital. Participants: 70 severe acute malnourished children aged 6 months to 59 months admitted in the NRC were randomized by computer generated random table. Intervention: 6 lakhs IU vitamin D was given intramuscularly on day one of therapy after an informed consent to the study group and other group was given only management of SAM. Main Outcome measure: outcome indicators of NRC i.e. cure rate, death rate, non-responders, relapse rate. Results: There was no significant difference in the outcome indicators of NRC i.e cured, death, non-response and relapse rate $(p=0.32)$ and average weight gain $(p=0.38)$ and length of stay $(p=0.42)$ between the two groups at discharge but wasting ( $\mathrm{p}=0.02$ on first, $\mathrm{p}=0.008$ on third and $\mathrm{p}=0.04$ on fourth follow ups respectively) improved significantly on follow ups. Conclusions: vitamin D supplementation does not have any significant improvement in the outcome indicators at discharge but significantly improves wasting on follow up.
\end{abstract}

Key word: Child, Nutritional Rehabilitation Centre, Outcome indicators, Severe acute malnutrition, Vitamin D.

\section{Introduction}

Vitamin D deficiency is considered to be the most common nutritional deficiency [1]. It has been estimated that 1 billion people worldwide have vitamin $\mathrm{D}$ deficiency or insufficiency [2]. The prevalence of vitamin D deficiency in Indian children is 50-90\% [3].

Various studies show that Vitamin D deficiency is also found in critically ill children [4,5,6]. Malnutrition accounts for about $35 \%$ of under-five mortality, of which $4.4 \%$ is specifically because of severe wasting. Severe wasting is estimated to account for around 400,000 childhood deaths each year [7]. In India, the

Manuscript received: $28^{\text {th }}$ April 2018

Reviewed: $7^{\text {th }}$ May 2018

Author Corrected: $15^{\text {th }}$ May 2018

Accepted for Publication: $20^{\text {th }}$ May 2018 prevalence of severe acute malnutrition (SAM) in children between 6 months to 5 years is $6.4 \%$ [8]. It had been estimated that prevalence of Vitamin D deficiency in malnourished children ranges from $31 \%$ to $61 \%$ [9].

Since SAM children have high rate of vitamin D deficiency and also have severe complications and critically ill, we aim to compareoutcome indicators in two groups of children with SAMin a nutritional rehabilitation Centre with or without vitamin D supplementation. 


\section{Methods}

We conducted a single blinded, parallel group randomized control trial without placebo. Children with severe acute malnutrition (SAM) with ages between 6 months to 59 months admitted in the nutritional rehabilitation centre (NRC) of a tertiary care centre from July 2015 to July 2016 were enrolled in our study. The study was cleared by ethical committee and is registered CTRI (CTRI registration number is CTRI/2016/07/007077).

SAM was defined as: Weight for height $(\mathrm{W} / \mathrm{H})$ less than -3SD (standard deviation) and/or Mid arm circumference $(\mathrm{MUAC})<11.5 \mathrm{~cm}$ and /or Edema of both feet [10]. Children with Underlying chronic disease (chronic renal failure, chronic liver disease, cholestasis), cerebral palsy with mental retardation / developmental delay, any medical transfer case, unstable vital parameters, any underlying cause for lack of weight gain other than malnutrition and with frank signs and symptoms of rickets were excluded from the study. The children without frank clinical and radiological features of vitamin D deficiency were randomized into two groups. Both the groups were treated in the NRC by the fully trained staff according to the recommendation given by world health organization (WHO) for admitted patients management of children with severe acute malnutrition except for the vitamin D supplementation to the study group [10]. The outcome indicators i.e. cured, non-responders, death, relapse, average length of stay and average weight gain were determined at the time of discharge as primary outcome. Cured was defined as patients who achieved $>15 \%$ weight gain from admission weight and/or free from medical complications and / or no edema for 10 days; Non-responders was defined as children who fail to achieve target weight during the treatment period; Relapse was defines as patients who again becomes eligible for admission in NRC within 2 months of being declared cured. Average weight gain was calculated by dividing the difference between discharge weight (grams) and minimum weight (grams) upon product of minimum weight (Kilograms) and number of days between minimum weight and discharge day. Defaulter was defined as patients who left the treatment before meeting the discharge criteria [8].

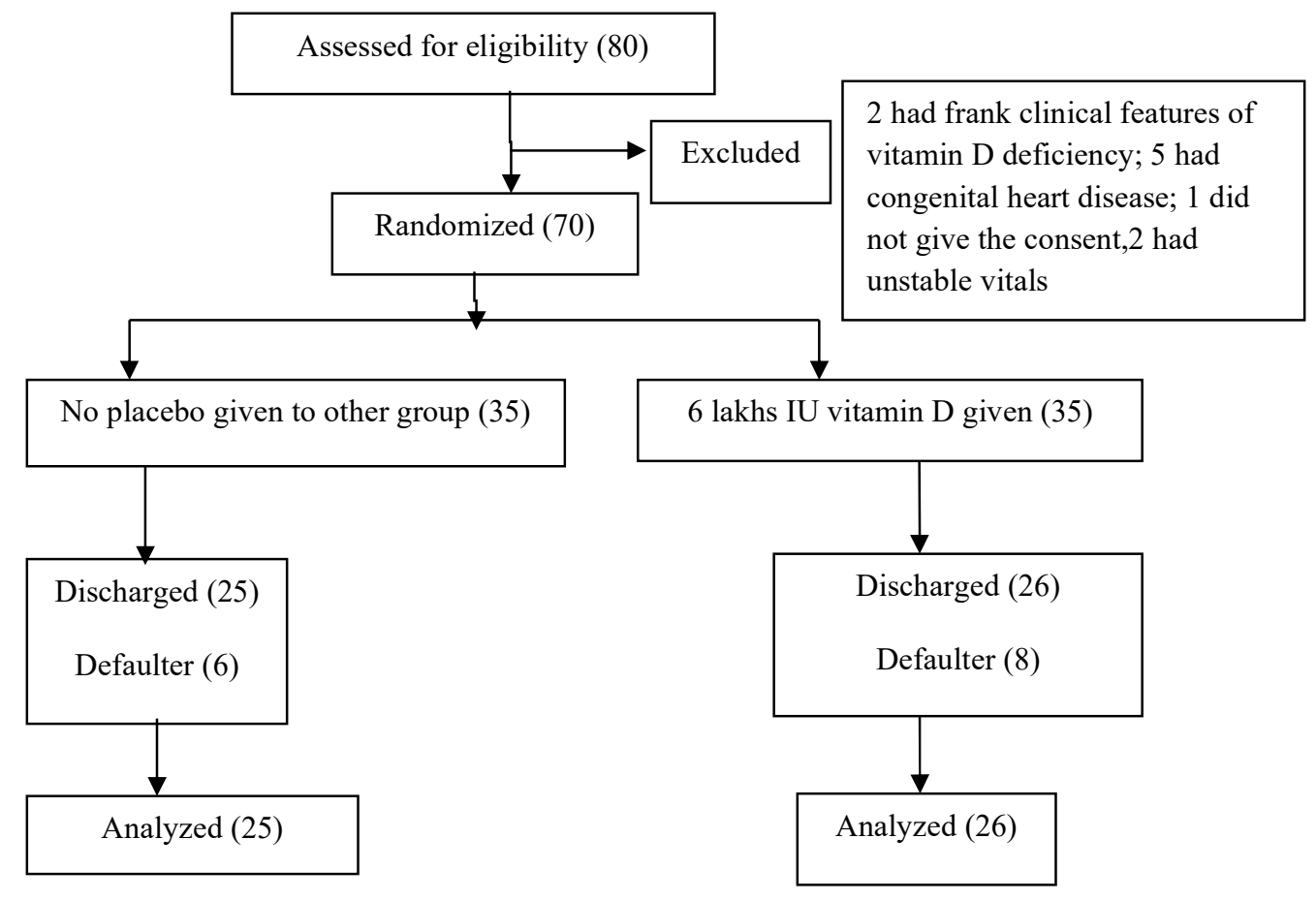

Figure-1: Randomized Control Trial to study the effect of high dose of vitamin D in children with SAM

The patients who were discharged were followed at every 15 days for 4 times and their W/H, Height for age (H/A), MUAC were recorded. After 6 months of Vitamin D supplementation an Ultrasound abdomen was done to look for any renal stones (as a side effect of high dose of Vitamin D supplementation).

Randomization- Randomization was done by the computer-generated randomization table. These randomized groups were enclosed in the opaque envelop, which were opened after enrollment of children in the study. The patients falling in study group were given High dose i.e., 6 lakh IU of vitamin D Intramuscularly on Day lafter a informed consent along 
Editorial

with the WHO recommended protocol for facility based care of SAM and other group was only given of management of SAM [7]. Patients attendant were unaware of the group in which they were treated.

Statistical methods- Chi square test was used to determine any significant association between vitamin D supplementation and outcome indicators such as cured, relapse, non-responders, death and unpaired student $\mathrm{T}$ test was used in outcome indicators such as average weight gain and length of stay between the two groups.

\section{Results}

Seventy children were included and randomized in two groups. The mean age was $16.98 \pm 9.49$ months with male: female ratio of 1.7:1. Mean weight, height, MUAC and body mass index (BMI) were $6.23 \pm 1.58 \mathrm{~kg}$ (95\% confidence interval [CI] 5.85-6.60), $69.53 \pm 7.48 \mathrm{~cm}(95 \%$ CI 67.74-71.31), $106.05 \pm 12.08 \mathrm{~cm}$ (95\% CI 103.16-108.93) and $12.71 \pm$ $1.59 \mathrm{~kg} / \mathrm{m}^{2}$ (95\% CI 12.33-13.09) respectively. Fortyfour (61.1\%) children had severe stunting (H/A < -3SD), 47 (65.3\%) children had severe wasting $(\mathrm{W} / \mathrm{H}<-3 \mathrm{SD})$

Twenty eight (38.9\%) children had history of recurrent pneumonia i.e. $>2$ episodes of chest infections in past 6 months and $36(50 \%)$ children had history of recurrent diarrhea i.e. $>2$ episodes of diarrhea in past 6 months. Multiparity was seen in $62(86.1 \%)$ of mothers, low BMI $(<18.5 \mathrm{~kg} / \mathrm{m} 2)$ was seen in $24(33.3 \%)$ mothers, $48(66.6 \%)$ families were below poverty line \& history of mixed feeding in $1^{\text {st }} 6$ months of life was seen in $49(68.1 \%)$ children, respectively. Acute gastroenteritis and pneumonia were the most common complication affecting 24 (33.3\%) \& 9 (12.5\%) children respectively. Other complications were chronic diarrhea, malaria, pyoderma, severe anemia, tuberculosis, meningitis etc. Twenty-five (34.7\%) children had history of timely initiation of breast feeding, 25 (34.7\%) children were exclusive breast fed, 24 (33.3\%) children had timely introduction of complementary feeding at 7 months, only $3(4.2 \%)$ children had history of adequate frequency of complementary feeding according to their age and 18 (25\%) children had Minimum dietary diversity. Twenty four $(33.3 \%)$ children had pallor, $10(13.8 \%)$ children had edema, $3(4.2 \%)$ children had vitamin A deficiency and frank clinical features of vitamin D deficiency were found only in 2 children.

Low serum calcium (normal range 1.12-1.23 mmol/L) was found in $51(70.8 \%)$ children, low serum phosphorous (normal $3.8-6.5 \mathrm{mg} / \mathrm{dL})$ levels were present in $6(8.3 \%)$ children and high serum alkaline phosphatase (145-420 IU/L) levels were present in 34(47.2\%) suggesting subclinical Vitamin D deficiency. The process of randomization is given in Figure 1. The baseline characteristics of randomized groups are given in table 1. There was no significant difference in the outcome indicators of NRC at discharge (table I and II).

Table- I: Baseline characteristics of randomized groups.

\begin{tabular}{|c|c|c|c|c|}
\hline S. No. & Characteristics & Control & Case & P value \\
\hline 1. & Age (months) & $16.44 \pm 9.97$ & $17.52 \pm 9.48$ & $>0.05$ \\
\hline 2. & Male: female & $1.91: 1$ & $1.69: 1$ & 0.66 \\
\hline 3. & Vegetarian (diet) & $29(83 \%)$ & $27(77 \%)$ & 0.550 \\
\hline 4. & Total duration of sun exposure (hours / day) & $2.20 \pm 1.02$ & $2.26 \pm 1.02$ & $>0.05$ \\
\hline 5. & Mean $\mathrm{Hb}(\mathrm{g} / \mathrm{dl})$ & $8.61 \pm 1.88$ & $8.64 \pm 1.92$ & $>0.05$ \\
\hline 6. & Edema & $9(12.8 \%)$ & $1(1.4 \%)$ & 0.007 \\
\hline 7. & $\begin{array}{l}\text { Mother supplementation of vitamin D \& calcium } \\
\text { during pregnancy }\end{array}$ & $6(17.1 \%)$ & $3(8.6 \%)$ & 0.477 \\
\hline 8. & Exclusive breastfeeding & $12(34 \%)$ & $12(34 \%)$ & 0.034 \\
\hline 9 & Timely introduction of complementary feeds & $10(28.5 \%)$ & $13(37.14 \%)$ & 0.33 \\
\hline 10 & Minimum meal frequency & $3(8.5 \%)$ & 0 & $>0.05$ \\
\hline 11 & Minimum dietary diversity & $14(40 \%)$ & $4(11.4 \%)$ & 0.008 \\
\hline 12 & Mean weight on admission & $6.08 \pm 1.73$ & $6.28 \pm 1.12$ & 0.30 \\
\hline 13 & Hypocalcemia N (\%) & $15(42)$ & $16(48)$ & 0.33 \\
\hline 14 & Hypophostasemia N (\%) & $4(11.4)$ & $2(6)$ & 0.288 \\
\hline 15 & High alkaline phosphatase $\mathrm{N}(\%)$ & $15(42)$ & $13(39)$ & 0.695 \\
\hline
\end{tabular}


Editorial

Table- II: Comparison of outcome indicators of NRC in two groups.

\begin{tabular}{|c|c|c|c|c|}
\hline S. No. & Outcome & $\begin{array}{c}\text { Control } \\
\text { N }(\%)\end{array}$ & $\begin{array}{l}\text { Cases } \\
\text { N (\%) }\end{array}$ & P value \\
\hline 1. & Cured & $25(71.4 \%)$ & $26(74.3 \%)$ & \multirow{4}{*}{$\begin{array}{c}0.32 \\
\text { (chi square test) }\end{array}$} \\
\hline 2. & Non -responder & $2(5.7 \%)$ & $1(2.9 \%)$ & \\
\hline 3. & Death & $2(5.7 \%)$ & 0 & \\
\hline 4. & Relapse & 0 & 0 & \\
\hline 5 & Length of stay (days) & $19.96 \pm 9.20$ & $19.26 \pm 8.22$ & $0.38 *$ \\
\hline 6 & Average weight gain (g/kg/day) & $9.12 \pm 3.97$ & $8.86 \pm 5.41$ & $0.42 *$ \\
\hline
\end{tabular}

*Unpaired student $\mathrm{T}$ test

Table- III: Weight for height comparison at admission, discharge and follow ups.

\begin{tabular}{|c|c|c|c|c|c|c|}
\hline $\begin{array}{c}\text { Weight for } \\
\text { height }\end{array}$ & $\begin{array}{c}\text { Admission } \\
(\mathrm{SD}=\mathrm{n})\end{array}$ & $\begin{array}{c}\text { Discharge } \\
(\mathrm{SD}=\mathrm{n})\end{array}$ & $\begin{array}{c}\text { Follow up I } \\
(\mathrm{SD}=\mathbf{n})\end{array}$ & $\begin{array}{c}\text { Follow up II } \\
(\mathrm{SD}=\mathrm{n})\end{array}$ & $\begin{array}{l}\text { Follow up III } \\
\quad(\mathrm{SD}=\mathbf{n})\end{array}$ & $\begin{array}{c}\text { Follow up IV } \\
(\mathrm{SD}=\mathbf{n})\end{array}$ \\
\hline \multirow[t]{4}{*}{ Control } & $1=0$ & $1=0$ & $1=0$ & $1=1$ & $1=1$ & $1=1$ \\
\hline & $2=1$ & $2=10$ & $2=6$ & $2=6$ & $2=3$ & $2=2$ \\
\hline & $3=10$ & $3=8$ & $3=14$ & $3=10$ & $3=9$ & $3=2$ \\
\hline & $4=18$ & $4=10$ & $4=5$ & $4=2$ & $4=1$ & $4=7$ \\
\hline \multirow[t]{4}{*}{ Cases } & $1=1$ & $1=4$ & $1=5$ & $1=3$ & $1=1$ & $1=2$ \\
\hline & $2=2$ & $2=9$ & $2=5$ & $2=6$ & $2=10$ & $2=9$ \\
\hline & $3=4$ & $3=8$ & $3=5$ & $3=4$ & $3=1$ & $3=5$ \\
\hline & $4=20$ & $4=6$ & $4=7$ & $4=4$ & $4=4$ & $4=2$ \\
\hline p-value* & 0.26 & 0.17 & 0.02 & 0.25 & 0.008 & 0.04 \\
\hline
\end{tabular}

$(1=$ Median to $-1 \mathrm{SD}, 2=1 \mathrm{SD}$ to $-2 \mathrm{SD}, 3=-2 \mathrm{SD}$ to $-3 \mathrm{SD}, 4=<-3 \mathrm{SD}) *$ Chi Square Test

There was a significant difference in $\mathrm{W} / \mathrm{H}$ on discharge and four follow ups (table III). There was no significant difference in the mean weight, height, BMI, MUAC average length of stay, average weight gain among the two groups

\section{Discussion}

Hypocalcemia was found in $51(70.8 \%)$ children, hypophosphatemia was present in $6(8.3 \%)$ children and high serum alkaline phosphatase levels were present in $34(47.2 \%)$ children which may be suggestive that children SAM suffer from subclinical vitamin D deficiency. There was no significant difference in outcome indicators of NRC, length of stay, average weight gain, $\mathrm{W} / \mathrm{A}$ and $\mathrm{H} / \mathrm{A}$ in children who were supplemented with high dose of vitamin D as compared to control group. There is significant improvement in wasting $(\mathrm{W} / \mathrm{H})$ in vitamin $\mathrm{D}$ supplemented group than in control group after discharge in first 2 months follow ups suggestive of some role of vitamin D in long term management of SAM.

Limitation of study was that the vitamin D levels could not be determined in our children due to financial problems. The strength was that study was conducted in NRC with trained staff with strict use of WHO Protocols for management of severe acute malnutrition.
So the two groups were equal in terms of therapy given to SAM except for the intervention we gave to the study group. Nabeta HW et al did a cross sectional study in Mulago hospital of Uganda on 158 children between ages 6 to 24 months and found low serum calcium in $50(43.5 \%)$ and low serum phosphorous in $7(6 \%)$ out of 117 malnourished children similar to our study [11].

Das RR et al did a systemic review of randomized control trial comparing treatment with vitamin D3 versus placebo in children $<5$ years of age old with pneumonia in 2013 and found no significant difference in the mean number of days of recovery in the two groups similar to our study similar to our study [12].

Although several studies showed that critically ill children have vitamin D deficiency and its level is related to the severity of illness, but no study as yet is found that shows any improvement in the outcome of ill children after vitamin D supplementation similar to our 


\section{Editorial}

study [4,6,13]. Walker SP and Golden MH in 1988 and later Richard SA et al in 2012 found that there is a lag in height gain before $85 \%$ of weight is achieved.

In our study also we found a significant improvement in $\mathrm{W} / \mathrm{H}$ but not height for age after vitamin D supplementation on initial 2 months of follow ups $[14,15,16]$. Long term follow ups to see improvement in height were not done in our study.

\section{Conclusion}

Although Vitamin D supplementation does not have any significant improvement in the outcome indicators of NRC at discharge but it significantly improves wasting i.e. the outcome of SAM children on follow ups. Improvement in wasting during follow ups indicates role of vitamin D in long term management of children with SAM.

\section{What is already known?}

Vitamin D levels are low in sick children

\section{What this study adds?}

Vitamin D supplementation has no significant improvement in the outcome of sick SAM children but it improves wasting on follow up

Acknowledgement- Thanks to the nutritional rehabilitation centre staff for their cooperation and to the statistician for his guidance. Special thanks to Dr.Arun Kumar Maurya for his support and encouragement.

Contribution: MM, PS and DKS, RR conceptualized the work design. MM, PS, and AS collected the Data. Data was analyzed and interpreted by MM, PS and AA. Manuscript was prepared MM, RR, DKS, and AS. Final revision and approval was given by all.

Funding: Nil, Conflict of interest: None initiated, Perission from IRB: Yes

\section{Reference}

1. Holick MF. Vitamin D: extraskeletal health. Rheum Dis Clin North Am. 2012 Feb;38(1):141-60. doi: 10.1016/j.rdc.2012.03.013. Epub 2012 Apr 12.

2. Holick MF. Vitamin D deficiency. N Engl J Med. 2007 Jul 19;357(3):266-81.

3. Harinarayan CV, Joshi SR. Vitamin D status in India-its implications and remedial measures. J Assoc Physicians India. 2009 Jan; 57:40-8.
4. Ponnaarmeni S, Angurana SK, Singhi S, Bansal A, Dayal D et al. Vitamin D Deficiency in critically ill children with sepsis. Pediatrics and international child health. 2016;36:15-211.

5. Hebbar KB, Wittkamp M, Alvarez JA, Mccracken CE, Tangpricha V. Vitamin D deficiency in pediatric critical illness. Journal of clinical and translational endocrinology. 2014; 1(4): 170-175. Available from URL: htt:/www.science direct.com/science/article/pill/ S2214623714000345. Accessed on 15/3/2017.

6. Shah SK, Kabra SK, Gupta N, Pai G, Lodha R. Vitamin D Deficiency and Parathyroid Response in Critically-ill Children: Association with Illness Severity and Clinical Outcomes. Indian Pediatr. 2016 Jun 8;53 (6): 479-84.

7. WHO. Guideline: Updates on the management of severe acute malnutrition in Infants and children. Geneva, World Health Organization 2013; 31. Available from URL: http:// www. who.int/ nutrition/ publications/ guidelines / updates_ management_ SAM_ infantand children/en/). Accessed on 12/8z/ 2016 .

8. Operational Guidelines on Facility based Management of children with Severe Acute Malnutrition, Ministry of Health and Family Welfare, Government of India, 2011. Available from: http:// www.nihf.org/ NCHRC- Publications/ Operational Guidelines. Accessed November 15, 2015.

9. Ejaz MS, Latif N. Stunting and micronutrient deficiencies in malnourished children.J Pak Med Assoc. $2010 \mathrm{Jul} ; 60(7): 543-7$.

10. WHO guidelines: updates on the management of severe acute malnutrition in infants and children. Geneva: World Health Organization. 2013. Available from URL: apps. who.int >iris 978941506328_eng. Assessed on 27/11/2017.

11. Nabeta HW, Kasolo J, Kiggundu RK, Kiragga AN, Kiguli S. Serumvitamin Dstatus in children with protein-energy malnutrition admitted to a national referral hospital in Uganda. BMC Res Notes. 2015 Sep7; 8: 418. doi: 10.1186/s13104-015-1395-2.

12. Das RR, Singh M, Naik SS. Vitamin D supplementation for treatment of acute childhood pneumonia: A systemic review. ISRN Pediatr. 2013. 


\section{Editorial}

13. Madden K, Feldman HA, Smith EM, Gordon CM, Keisling SM, Sullivan RM, Hollis BW, Agan AA, Randolph AG. Vitamin D deficiency in critically ill children. Pediatrics. 2012 Sep; 130(3):421-8. doi: 10. 1542 / peds. 2011-3328. Epub 2012 Aug 6.

14. Walker SP, Golden MH. Growth in length of children recovering from severe malnutrition. Eur J Clin Nutr. 1988 May;42(5):395-404.
15. Richard SA, Black RE, Checkley W. Revisiting the relationship of weight and height in early childhood. Adv Nutr. 2012 Mar 1;3(2):250-4. doi: 10.3945/an.111. 001099.

16. Richard SA, Black RE,GilmanRH, Guerrant RL, Kang $\mathrm{G}$ et al. Wasting is associated with stunting in early childhood. J Nutr. 2012Jul; 124(7): 1291-6.

\section{How to cite this article?}

Maurya M, Sharma P, Srivastava A, Rai R, Singh D.K. Effect of vitamin D supplementation in children with severe acute malnutrition in a nutritional rehabilitation centre: a randomized controlled trial. Int J Pediatr Res. 2018;5(5):278283.doi:10.17511/ijpr.2018.105.07. 